\title{
A doença no Jornalismo: análise do noticiário de capa da revista Veja (1968-2014) ${ }^{1}$
}

\author{
Luiz Marcelo Robalinho Ferraz \\ Doutor; Fundação Oswaldo Cruz, Rio de Janeiro; RJ, Brasil \\ marcelo.robalinho@gmail.com
}

\section{Resumo}

O jornalismo se constitui numa esfera de grande importância na atualidade para compreendermos as noções de saúde e doença. Pensando nisso, tomamos como objeto empírico o semanário de informação Veja, do qual investigamos o noticiário de capa produzido entre os anos de 1968 e 2014 para avaliar a ideia de doença construída pela revista. Num primeiro momento, examinamos quantitativamente a cobertura em relação aos assuntos ligados à saúde e ao noticiário geral. Em seguida, aprofundamos o olhar qualitativo a partir das três moléstias mais noticiadas dos principais grupos: o câncer (crônicodegenerativa), o HIV/AIDS (infectocontagiosa) e a depressão (transtornos mentais). Mesmo sendo doenças de grupos distintos, a cronicidade é a principal característica que as aproxima. Enfatizando a medicalização e o cuidado crônico, a Veja reforça a importância do leitor na autorregulação como forma de controle e/ou prevenção.

\section{Palavras-chave}

Doença. Jornalismo. Medicalização. Revista Veja. Saúde.

\section{Introdução}

Este artigo analisa a noção de doença construída pelo jornalismo de revista. Tomamos como material empírico o semanário de informação Veja, do qual analisamos o noticiário de capa. A opção pela Veja se deu devido ao interesse em estudar a construção discursiva desse veículo impresso de ampla circulação nacional, atualmente em primeiro lugar no Brasil no

\footnotetext{
${ }^{1}$ Este artigo deriva da tese Doença, uma construção (também) jornalística: estudo cartográfico do noticiário de capa do semanário de informação Veja (1968-2014), de Ferraz (2015).
} 
segmento (1.130.089 exemplares) e segundo no mundo (ABRIL, 2017), além de ser o semanário do gênero mais longevo no país. 0 apelo da saúde nas suas publicações, principalmente dos anos 1990 para cá, quando o assunto começou a ter mais destaque no noticiário, foi outra razão da escolha, o que nos ajudou a aprofundar o olhar a respeito dos sentidos construídos sobre a doença.

Diverso do jornal, geralmente diário, a revista semanal de informação permite maior tempo para a produção das reportagens e matérias. Também possui um jornalismo menos factual e, em tese, mais analítico, diferentemente da internet, da televisão e do rádio, que trabalham com o acontecimento sob a lógica do imediatismo. Sendo assim, a produção tende a "[...] explorar novos ângulos, buscar notícias exclusivas, ajustar o foco para aquilo que se deseja saber, conforme o leitor de cada publicação." (SCALZO, 2011, p. 41). Ou, como segundo a própria Veja informa, “[...] seleciona os assuntos mais relevantes da semana [...]” e “[...] trata da notícia com mais profundidade [...]" que outros meios (ABRIL, 2017, p. 7).

Do ponto de vista metodológico, este paper traz um painel estatístico sobre a cobertura de capa da Veja, com o intuito de situar melhor o noticiário sobre doença em relação à saúde e às demais temáticas. Para tanto, consideramos a doença um subtema da saúde. Analisamos quantitativamente a produção jornalística da revista entre as edições 1 (11 set. 1968) e 2406 (31 dez. 2014). 0 painel serviu de base para as discussões sobre a forma como a revista produziu a sua ideia de doença.

Depois, selecionamos as moléstias mais noticiadas nos três principais grupos: o câncer (crônico-degenerativa), o HIV/AIDS (infectocontagiosa) e a depressão (transtorno mental) para a avaliação qualitativa. 0 propósito foi compreender as fronteiras e definições do que é considerado "normal" e "saudável", além do caráter simbólico da noção de doença engendrada nos/pelos meios de comunicação, a partir das patologias mais representativas jornalisticamente e, ao mesmo tempo, diferentes entre si, em função das características.

Ao estabelecer uma relação entre jornalismo e doença, o artigo traz consigo dois pressupostos subjacentes. 0 primeiro diz respeito à própria ideia de doença, entendida aqui como algo socialmente construído e que, portanto, não se reduz ao biológico apenas, ainda que essa dimensão não esteja sendo negada. 0 modo como sociedades definem, conceituam, reagem e atribuem sentido aos agentes patológicos varia conforme os contextos históricos e culturais. Sendo assim, a dimensão biológica não pode ser vista como algo estanque, e sim estruturada simbolicamente em diferentes épocas. 
O segundo pressuposto é que a concepção de doença não é homogênea, mas implica diferentes perspectivas, seja a lógica do saber médico-científico, seja a dos pacientes e familiares, seja a das autoridades sanitárias, bem como a de outros atores sociais, como o jornalismo, que se configura como foco privilegiado do nosso trabalho. Sendo este um espaço discursivo bem particular, os veículos relatam os fatos no espaço público, selecionando e construindo os acontecimentos por meio de um contrato de comunicação no qual busca informar a sociedade e garantir a legitimidade democrática do seu trabalho, dentro de uma lógica também econômica, que implica a sobrevivência diante da concorrência (CHARAUDEAU, 2006, 2009).

Perpassada por discursos de outros domínios, a produção jornalística não significa uma mera reprodução do real. Ao contrário disso, o jornalismo produz seus discursos a partir de um entrelaçamento de diferentes vozes para o estabelecimento da sua própria voz sob a pretensa ideia de objetividade, neutralidade e imparcialidade do relato. É uma peculiaridade do campo que confere autoridade institucional distinta dentre os demais agentes sociais no contrato firmado com o seu público. Por isso, a menção às preposições "em" e "por", neste artigo, ao tratar da noção de doença construída nos/pelos veículos de comunicação é intencional, tendo em vista que o jornalismo não apenas reflete as representações correntes na sociedade, como também, ele mesmo, constrói as suas próprias representações, num permanente jogo de reflexão e refração.

Não sendo produto de um conhecimento privilegiado apenas do saber médicocientífico, a doença está imiscuída na nossa cultura de significados e valores. Por isso, para compreendermos como são constituídos os sentidos sobre doença, é necessário olharmos também para a instância jornalística, entendendo-a inserida num campo de práticas, no qual o fazer cotidiano dos veículos foi instituindo olhares específicos sobre o tema, através de rotinas e lógicas particulares na produção da notícia (FERRAZ, 2015).

\section{0 apelo da doença no noticiário}

No noticiário, a divulgação de notícias sobre doenças costuma ter um forte apelo junto ao público, devido ao risco que os males representam para a vida das pessoas. Isso se exacerba nas epidemias. Como acontecimentos singulares no ambiente social e no universo discursivo (FOUCAULT, 2006; 2007), esses eventos se inserem no contexto das calamidades públicas, sobretudo quando se tratam de doenças transmissíveis. Algo que já era comum 
desde o início do século $\mathrm{XX}$, quando esses tipos de doenças provocavam mais óbitos, a exemplo da pandemia de gripe espanhola entre 1918 e 1919, atraindo a atenção da imprensa brasileira na época (BERTUCCI, 2004; FARIAS, 2008; SOUZA, 2007).

Dos anos 1980 para cá, o apelo midiático das moléstias infecciosas adquiriu nova importância, com o aparecimento das doenças emergentes, como a AIDS, a dengue, a gripe A (H1N1) e, mais recentemente, a zika. A AIDS teve um maior impacto, ao pôr em xeque o aparente controle que se imaginava ter sobre as doenças infecciosas (MOULIN, 2009). 0 aumento das crônico-degenerativas, como os males do coração, os cânceres e o diabetes, desde meados do século XX, também vem atraindo o olhar da mídia. Entre elas, o câncer vem tendo especial destaque (JURBERG et al., 2012; CLARK, 2013). Dentre os transtornos mentais, que integram o grupo das crônicas, a depressão chama a atenção dentro e fora do Brasil (EHRENBERG, 2004; SAINT CLAIR, 2012; VAZ, 2012; VAZ; PORTUGAL, 2012).

Importante observar as relações estreitas entre jornalismo e saúde. De tema de notícias e reportagens, a saúde passou a ser citada nos guias de comunicação como uma área em expansão. No Manual de jornalismo, Hohenberg (1962) dedicou um capítulo para tratar disso nos periódicos, considerando um dos aspectos mais estimulantes no começo dos anos 1960. Enquadrada na editoria medicina, a saúde era um assunto com crescente interesse, ao lado da ciência e educação. A revista $O$ Cruzeiro $^{2}$, uma das principais semanais brasileiras da primeira metade do século XX, já falava de saúde (PORTELA, 2009). Desde 1968, a Veja possuía a seção "Medicina”, em que eram veiculados os textos sobre saúde e doença.

No começo do século XXI, a saúde ocupava a segunda colocação nos assuntos de interesse dos leitores de jornais norte-americanos ao lado de alimentação, habitação, turismo e moda. Também se verificava um aumento de interesse no Brasil e na Espanha (TABAKMAN, 2013). Com o passar do tempo, a saúde se converteu num dos temas de longa duração. Bases do jornalismo de revista, de acordo com Benetti (2013), eles costumam ser retomados, a partir de certos fatos e eventos.

Espécie de meta-acontecimentos, diz a autora, esses fatos e eventos funcionam como pretextos para novas abordagens dos temas de longa duração para atrair a atenção do leitor. Sob a lógica do risco, do cuidado crônico e da medicalização, o noticiário passou a

\footnotetext{
2 Lançada em 1928 pelo grupo Diários Associados, O Cruzeiro foi sucesso editorial nos anos 50, deixando de circular temporariamente em 1975. Retornou em 1977, mas foi extinta em 1983 (PORTELA, 2009).
} 
recomendar a população, num tom normativo, a cuidar da saúde e do corpo, adotando práticas ditas "seguras" para se salvaguardar da possibilidade de adoecer no futuro.

Nesse cenário, os fatores de risco - as características do indivíduo ou do ambiente onde vive que aumentam as chances de vir a adoecer (CASTIEL; GUILAM; FERREIRA, 2010) - tornaram-se um elemento capital na produção de sentidos, pela potencialidade que a exposição a certo hábito representa. 0 contexto do risco parece ser mais evidente nas doenças crônicas, que, muitas vezes, prolongam-se para a vida toda. Nelas, a experiência de estar em risco converge com a própria experiência da doença em que o diagnóstico, o tratamento e a gestão da enfermidade buscam reduzir os efeitos das patologias, sobretudo as assintomáticas. Em outras situações, propõe-se diminuir as chances de adoecimento (ARONOWITZ, 2009). O cuidado crônico passou a ser um elemento preponderante pela responsabilidade permanente que o indivíduo assume sobre a sua saúde, sendo mais enfatizado no discurso jornalístico, em função de uma lógica medicalizante, na qual o sujeito amplia a temporalidade do cuidado para além dos sintomas, muitas vezes até a morte.

\section{Causalidade e temporalidade na relação entre jornalismo e saúde}

Na relação entre jornalismo e saúde, a noção de causalidade é importante. Termo caro ao pensamento científico, a causalidade integra o conjunto das bases epistemológicas da epidemiologia, sendo útil na mensuração de saúde das populações (COUTINHO; ALMEIDA FILHO; CASTIEL, 2011). Ligada a uma lógica cartesiana, busca valorizar a evidência do método. Para explicar a ocorrência das doenças ou outros eventos ligados à saúde, a causalidade contribui para calcular as estimativas com o apoio da estatística.

0 " $\mathrm{x}$ " da questão está no dimensionamento dado a esse nexo causal. A probabilidade acaba sendo transformada numa previsão ou, numa análise mais radical, em quase "certeza" futura, a depender dos hábitos de vida adotados, sobretudo quando as informações produzidas circulam pela imprensa, incentivadas pela medicina, a ciência ou mesmo a saúde pública, através da divulgação de dados estatísticos no noticiário.

Nas mídias, o acontecimento sempre é construído, pois o sentido nunca é dado antecipadamente. Para Charaudeau (2006), o sentido se dá por meio de um duplo mecanismo:

a) de transformação, que consiste em dar significação ao mundo (nomear, qualificar, narrar e argumentar); 
b) de transação, que tem por finalidade dar significação ao ato da linguagem (identidade do outro, efeito sobre esse outro e relação que se pretende instaurar e regulação de todos os parâmetros anteriores).

O processo de transação é que comanda o de transformação, já que o homem fala “[...] para se colocar em relação com o outro porque disso depende a própria existência, visto que a consciência de si passa pela tomada de consciência da existência do outro, pela assimilação do outro e ao mesmo tempo pela diferenciação com relação ao outro." (CHARAUDEAU, 2006, p. 42). Considerando o contrato um "acordo" tácito no qual se funda a relação entre os interlocutores num processo comunicativo (meio de comunicação e público, no caso da esfera jornalística), os veículos ocupam posição de mediadores entre o acontecimento e cidadão, buscando a legitimidade democrática (CHARAUDEAU, 2006).

Associando isso à ideia de causalidade, ela pode ser observada num contexto diverso da saúde. No contrato de comunicação, o processo de transformação pelo qual passa o acontecimento já na fase de produção da notícia o insere numa lógica causal para poder ser organizado e interpretado. “Opera-se uma construção semântica do acontecimento, na qual ele é enquadrado, enredado a outros elementos, como agentes, circunstâncias e motivos, e é inscrito numa intriga, em que recebe um início e um desfecho." (LAGE, 2014, p. 80).

Como uma construção social, o texto jornalístico insere o público em um contrato implícito que extrapola a norma da objetividade norteadora da prática profissional do jornalista, "[...] alcançando os ideais de equilíbrio, pluralidade, abrangência temática e responsabilidade no trato da informação." (BENETTI, 2007, p. 3). Aliado às noções de neutralidade e imparcialidade que predominam alegoricamente na construção do discurso, os meios advogaram para si a credibilidade como principal capital simbólico. Algo que vem da confiança construída através dos acontecimentos retratados, o que dá uma ideia de verdade aos relatos produzidos (RIBEIRO, 2005).

Para Benetti (2013), a credibilidade é uma qualidade reconhecida pelo outro. "É preciso que os atributos sejam construídos fora do enunciador, embora sejam convenientemente replicados por ele." (BENETTI, 2013, p. 48). No contrato, fala-se da atualidade, do que geralmente acabou de ocorrer, gerando uma ideia de presentificação. A finalidade de fazer conhecer os eventos do mundo (atualidade) à sociedade confere ao jornalismo uma legitimidade de falar em nome do processo democrático. Está ligado à factualidade (falar sobre os fatos) e à explicação (expor causas e efeitos). As normas contribuem para a construção dessa ideia de verdade. Nesse sentido, a chave-tempo é 
fundamental para compreendermos a forma de organização do discurso no jornalismo de revista.

Nesse tipo de jornalismo, a temporalidade se distingue pela sua periodicidade. Afirma Antunes (2014) que a relação entre acontecimento e notícia no jornalismo é determinante para a compreensão da temporalidade e do sentido de atualidade. Os jornalistas, as empresas, as práticas jornalísticas e as notícias, todos são articulados pelo tempo. "A 'periodicidade', o 'imediatismo' e a 'atualidade' aparecem como facetas desse sistema articulado para 'capturar' os acontecimentos do mundo." (ANTUNES, p. 159, grifos do autor). 0 que o jornalismo faz é equalizar os diferentes tempos no seu discurso. Assim, a "atualidade" conota uma ideia de presente, apesar de o fato ser passado. 0 que está subjacente é a noção do contemporâneo.

É importante refletir sobre o contemporâneo na construção da história do presente, levando-se em conta os relatos dos semanários de informação. Neles, a narrativa impõe um jornalismo mais analítico e menos factual, com notícias exclusivas e novos ângulos (SCALZO, 2011). Além disso, cria um presente mais alongado por um fato que se inscreve no passado da semana anterior ou até mesmo um pouco mais distante, a depender dos enfoques dados, especialmente os assuntos ligados àa saúde e doença, que tendem a ser mais "frios" que pautas ligadas à política ou à economia nacional, por exemplo.

\section{A presença da saúde e doença em Veja}

Pelas análises às 4.531 manchetes principais e secundárias de capa publicadas na revista Veja entre as edições 1 (11 set. 1968) e 2406 (31 dez. 2014), o noticiário sobre saúde apareceu em quinto lugar na cobertura geral, atrás das temáticas "Brasil", "Internacional", "Economia e Negócios" e "Cultura". A situação se altera quando fazemos uma análise em relação a três fases em separado (1968-1983, 1983-1996 e 1996-2014)³. Inicialmente na oitava posição, a cobertura sobre os temas ligados à saúde foi para a sexta posição no segundo período. Na terceira fase, pulou para o terceiro lugar.

Considerando todas as seções da revista, foram publicados 401 textos sobre saúde. 0 Gráfico 1 mostra as variações ocorridas com o noticiário. Nele, enxergamos duas tendências

\footnotetext{
3 A identificação das três fases no nosso corpus tem a ver com a forma de a Veja localizar o texto sobre saúde e doença e nomear o campo temático ao qual o assunto está atrelado. Na primeira fase (1968-1983), as reportagens eram enquadradas na seção "Medicina". Na segunda fase (1983-1996), criou-se a seção "Saúde", passando a dividir espaço com "Medicina", enquanto que, na terceira (1996-2014), apareceram subseções ("Coração", "Câncer", "Cigarro", "Drogas", "Biologia”, "Sexo", "Ginástica”, "Longevidade”, "Beleza”, “Dieta”, “Genética”, "Mulher”, “Ginástica”), ampliando os espaços de concorrência.
} 
evidentes ${ }^{4}$. A primeira foi de 1969 a 1996, abrangendo o primeiro e o segundo período da Veja, quando o total de reportagens de capa anuais variou de zero (valor mínimo) a cinco (valor máximo). Embora o número absoluto e o percentual tenham aumentado, foi um momento em que a curva de variação apresentou certa homogeneidade entre essas duas fases, com uma média de 2,6 manchetes por ano.

A maior alteração ocorreu na terceira fase, entre 1996 e 2014, quando a curva apresentou uma onda de aumento, com as manchetes de capa variando de 5 (mínimo) a 16 (máximo) por ano e uma média de 10,4 títulos. Mesmo com os decréscimos em 2013 e 2014, os números foram maiores que os registrados em 1997, 2000, 2001, 2002 e 2003. Isso reforçou a importância dessa última fase, em que a saúde e a doença passaram a ter maior destaque na cobertura em relação às demais temáticas, muito provavelmente pela maior presença em manchetes secundárias.

Gráfico 1 - Total de manchetes sobre saúde por ano de Veja, 1968-2014

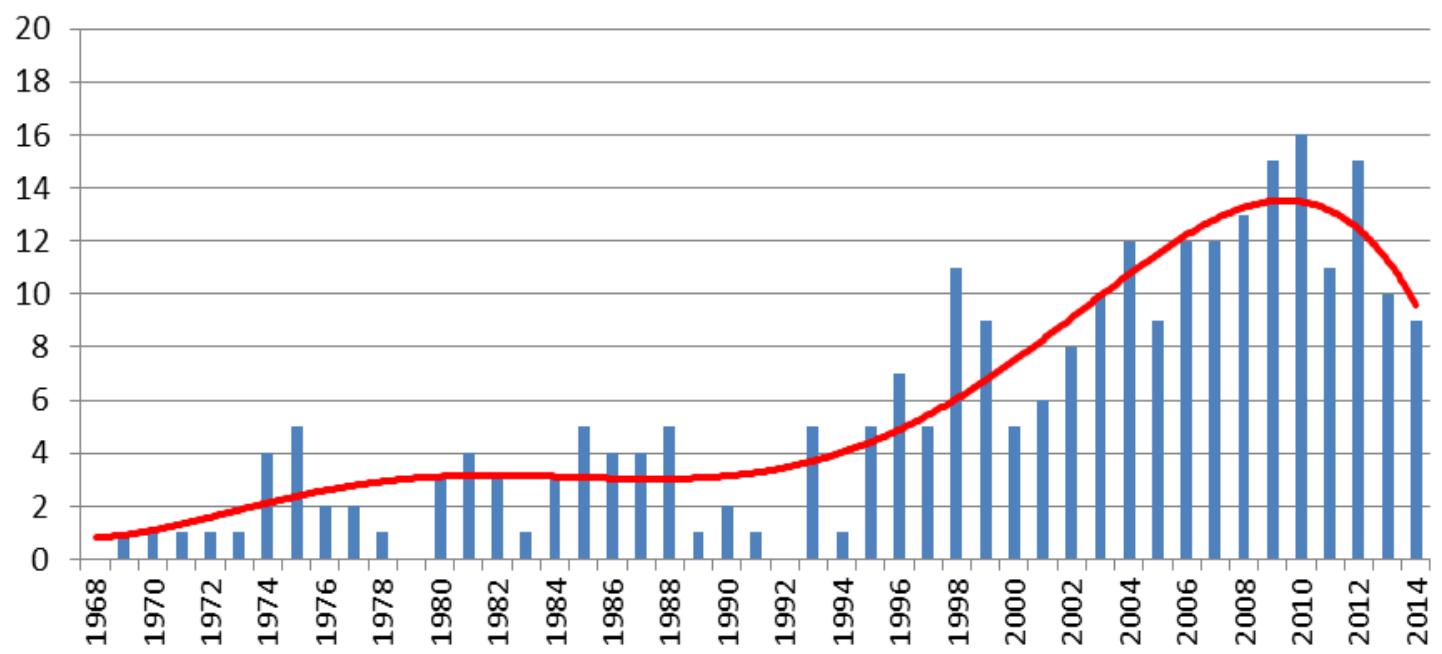

Fonte: Elaborado pelo autor.

Do total de reportagens sobre saúde, 343 fizeram referência a doenças (86\%) de forma restrita, como uma menção dentro de outro assunto, ou mais amplamente, como foco da reportagem. A vinculação à ideia de risco é essencial para pensarmos no maior apelo jornalístico da doença, se levamos em conta o deslocamento ocorrido com a noção na contemporaneidade - tornando o normal raro e o patológico, média da sociedade (VAZ; PORTUGAL, 2013). No contexto de medicalização, em que fenômenos antes considerados

${ }^{4}$ Excetuamos mais uma vez o ano de 1968 por estar incompleto no conjunto de reportagens. 
comuns da natureza humana são interpretados pela medicina como doenças (CONRAD, 1992; 2007; CONRAD; SCHNEIDER, 1980; ZOLA, 1972; CLARKE et al., 2003), os indivíduos se tornam mais doentes ou potencialmente doentes, singularizando a experiência da doença, sobretudo na mídia, em que a saúde ocupa um lugar entre os assuntos de maior interesse.

Mesmo saudável, o sujeito é "convidado" a mudar ou manter o seu estilo de vida no presente, inclusive pelo consumo de medicamentos, levando alguns autores a denominarem a medicalização em farmaceuticalização ou farmacologização (BORCH-JACOBSEN, 2013; WILLIAMS; MARTIN; GABE, 2011; CAMARGO JÚNIOR, 2013; VAZ; PORTUGAL, 2012). Usados para evitar a ocorrência de uma doença, os remédios contribuem por tornar a intervenção à saúde, antes comum com o aparecimento de sintomas, agora permanente durante a vida. A ênfase da Veja aos remédios é indicadora disso. Por meio da abordagem sobre prevenção e/ou tratamento, a doença vai se inserindo mais nas pautas.

O câncer foi a patologia mais noticiada no grupo das moléstias crônicas (163). Dentre as neoplasias, o câncer de mama apareceu em primeiro lugar (55), seguido do câncer de próstata e de pulmão (41 cada), de cólon, reto e ânus (30) e de intestino (28), além da leucemia (18), de pele e de fígado (com 17 cada) e o de colo de útero e de estômago (15 cada). A distribuição dos tipos se assemelha ao perfil de ocorrência no Brasil, em que coexistem tipos ligados a melhores condições socioeconômicas (caso da mama, da próstata e do colorretal), típicos de países desenvolvidos, e à situação de pobreza (como de colo de útero e estômago), comuns de países em desenvolvimento (KOIFMAN, S; KOIFMAN, R., 2003).

Estabelecendo uma correlação dos tipos mais noticiados com os mais frequentes na população brasileira por gênero, segundo estimativas do Instituto Nacional do Câncer (INCA) para 2014 e 2015 (Figura 1), próstata, pulmão, cólon e reto e estômago são os quatro cânceres mais frequentes na população masculina. 
Figura 1 - Distribuição proporcional dos dez tipos de câncer mais incidentes estimados para 2014 por sexo, exceto pele não melanoma* - Brasil, 2014

\begin{tabular}{|c|c|c|c|c|c|c|c|}
\hline Localizaçăo primária & casos & $\%$ & & & _Localização primária & - $^{\text {casos }}$ & $-\%$ \\
\hline Próstata & 68.800 & $22,8 \%$ & Homens & Mulheres & Mama Feminina & 57.120 & $20,8 \%$ \\
\hline Traqueia, Brônquio e Pulmão & 16.400 & $5,4 \%$ & & & Cólon e Reto & 17.530 & $6,4 \%$ \\
\hline Cólon e Reto & 15.070 & $5,0 \%$ & & & Colo do Útero & 15.590 & $5,7 \%$ \\
\hline Estômago & 12.870 & $4,3 \%$ & & & Traqueia, Brônquio e Pulmão & 10.930 & $4,0 \%$ \\
\hline Cavidade Oral & 11.280 & $3,7 \%$ & & & Glândula Tireoide & 8.050 & $2,9 \%$ \\
\hline Esôfago & 8.010 & $2,6 \%$ & & & Estômago & 7.520 & $2,7 \%$ \\
\hline Laringe & 6.870 & $2,3 \%$ & & & Corpo do Útero & 5.900 & $2,2 \%$ \\
\hline Bexiga & 6.750 & $2,2 \%$ & & & Ovário & 5.680 & $2,1 \%$ \\
\hline Leucemias & 5.050 & $1,7 \%$ & & & Linfoma năo Hodgkin & 4.850 & $1,8 \%$ \\
\hline Sistema Nervoso Central & 4.960 & $1,6 \%$ & & & Leucemias & 4.320 & $1,6 \%$ \\
\hline
\end{tabular}

*Números arredondados para 10 ou múltiplos de 10.

Fonte: Brasil (2014).

Já nas mulheres, a incidência maior é de mama, cólon e reto, colo do útero e pulmão. Na população como um todo, o tumor de pele é o mais incidente, embora no noticiário tenha aparecido em sétimo lugar, atrás da leucemia, que apareceu em nono na incidência entre os homens e em décimo entre as mulheres. Pela relevância epidemiológica, o câncer ganha espaço não só nas agendas políticas, como também na imprensa. Apesar disso, vemos diferenças entre os dados, em parte pela evolução do campo médico-científico na identificação e no tratamento de certas neoplasias, em parte pelo apelo jornalístico que determinados tipos de tumor têm para a revista, como mama, próstata e pulmão.

No grupo das doenças infecciosas, o HIV/AIDS foi a que mais apareceu (56) no período estudado. Sua presença ocorreu a partir da segunda fase da revista (1983-1996), quando o vírus do HIV e os primeiros casos da doença foram descobertos e divulgados na imprensa no início dos anos 1980. A ampla difusão de notícias tornou a AIDS a primeira doença midiática, em grande parte pelo fato de os meios de comunicação terem anunciado o seu surgimento, acompanhado de perto a sua evolução e operado "() a passagem das informações sobre a doença do domínio médico e científico para o registro social." (SPINK et al., 2001, p. 852).

Já entre os transtornos mentais, a depressão foi mais noticiada (89), ganhando relevância entre 1996 a 2014, concentrando 87\% das 89 menções. Período em que foi reconhecida como transtorno psíquico pela Veja, tornando-se um mal individual, "[...] passível de ser compreendido por discursos de competência técnica, sejam eles a medicina, a psicanálise, as terapias cognitivo-comportamentais, as neurociências, a psiquiatria 
biológica ou as diversas terapias chamadas alternativas.", como afirma Saint Clair (2012, p. 38).

\section{0 atravessamento da condição crônica}

Mesmo sendo as três pertencentes a grupos distintos, a cronicidade é a característica que aproxima o câncer, o HIV/AIDS e a depressão na noção de doença construída pela Veja, pelo fato de serem potencialmente tratáveis. No caso do HIV/AIDS, a terapia medicamentosa afastou a morte da experiência do sujeito que adere ao acompanhamento médico e ao tratamento, sobretudo em meados dos anos 1990. Das três, o câncer surgiu primeiro no noticiário, na edição 239 (VEJA, 1973). Na década de 1970, as neoplasias foram pouco abordadas, em função do contexto da cobertura sobre saúde na época, que buscava enfatizar mais as falhas e as carências do sistema público.

Nos primeiros 21 anos da revista, a tendência do noticiário sobre o câncer revelou-se estatisticamente baixa e relativamente indefinida, com uma média anual de manchetes de 1,47. A mudança ocorreu de 1995 a 2010, quando as reportagens anuais variaram entre 4 (mínimo) e 13 (máximo). Isso se explica pela maior recorrência do câncer como tema principal de capa, relacionando-o ao apelo dos registros de casos novos e mortes e às vitórias da medicina e da ciência no tratamento.

Mesmo não sendo um fato em si, os números se converteram em elementos desencadeadores das reportagens publicadas, podendo relacioná-los à magnitude do câncer como valor-notícia, pensando nesse conceito jornalístico (GALTUNG; RUGE, 1965; SODRÉ, 2009). Foram acompanhados do anúncio de tratamentos para combater a doença, uma forma de alertar para a gravidade (atrair a atenção) e oferecer a solução (sugerir a terapêutica).

Pelas capas presentes na Figura 2 o sistema enunciativo é baseado na ideia de morte. Na edição 1440 (VEJA, 1996), na imagem do lado esquerdo, o sumário da manchete principal informa que o câncer é a "doença que mata 90 mil brasileiros por ano", além de indicar que a reportagem aponta os tumores mais letais e o "que fazer para prevenir o mal". 
Figura 2 - Capas sobre câncer enfatizando a morte - Veja, 1996 e 2003

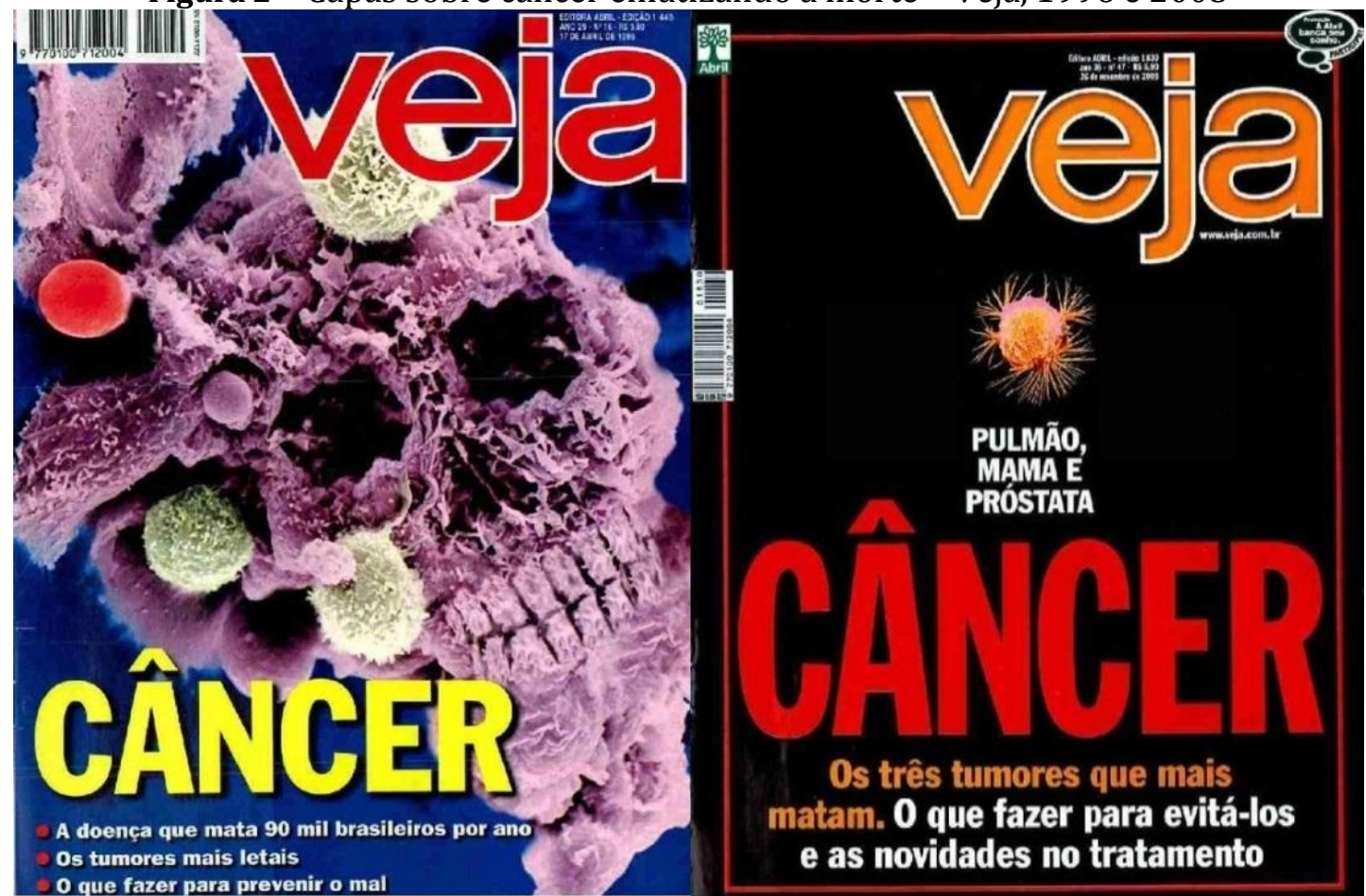

Fonte: Adaptado de Veja (1996; 2003), ed. 1440, 17 abr. 1996, e ed. 1830, 26 nov. 2003.

A diagramação da edição 1440 ressalta a morte através de uma caveira envolta de bolas nas cores verde e vermelha, uma alusão aos tumores que se formam no organismo. 0 azul (ao fundo) é a cor mais fria, representando o lado mais sombrio, se comparado ao branco. Dá a ideia de abrir o espaço, deixando passar o frio, com capacidade de produzir um efeito de distância e infinito (HELLER, 2013). Somado ao espectro da caveira, a Veja trabalha a representação da morte em imagem e texto, buscando atrair a atenção.

Já na edição 1830 (26 nov. 2003), na imagem do lado direito, a diagramação usa o vermelho sob um fundo preto, cor associada à morte, algo corrente nas capas da revista sobre saúde (FRANÇA, 2011). A representação imagética do tumor é mais clara. A morte surge na manchete, através de uma frase escrita em laranja (Os três tumores que mais matam), cor que pode ser usada para representar o perigo (HELLER, 2013). A estratégia enunciativa seria uma maneira de enfatizar a palavra "câncer" em letras grandes e na cor vermelha, que representa o sangue e a vida. Na reportagem, as notificações e as mortes são o mote para tratar do desenvolvimento das técnicas de diagnóstico, da criação de drogas mais potentes e do aprimoramento das medidas de prevenção. 
Um dos diferenciais está na maior ênfase dada à morte na manchete interna. Se em 1996 ressaltava-se o combate à doença (A guerra ao câncer), o título em 2003 reforçou o caráter funesto dos tumores (Malignos, comuns e traiçoeiros), realçando a importância da prevenção, a ponto de utilizar um tom imperativo ao final do texto.

Se você fuma, largue o cigarro já. Se você é sedentário, comece a se mexer. Se sua dieta é desregrada, trate de se alimentar direito. Se você não segue a rotina de exames básicos, marque uma consulta com o seu médico amanhã. (NEIVA, 2003, p. 151).

Comum na propaganda, o modo imperativo dos verbos é uma forma de persuadir a audiência, buscando convencê-la a fazer o que está sendo dito. No jornalismo de informação, é pouco recorrente, ao contrário do que faz a Veja, que tenta ordenar medidas de prevenção ("largue o cigarro já", "comece a se mexer", "trate de se alimentar direito", "marque uma consulta com o seu médico amanhã"). 0 uso de imperativos é revelador do forte traço de opinião contido em Veja, uma característica desenvolvida nas últimas décadas no noticiário sobre saúde. Embora o flagelo seja coletivo (o câncer), as recomendações incentivam um bem-estar individual. Uma característica individualizante em nome do coletivo.

O HIV/AIDS surgiu depois. A identidade dos famosos foi o primeiro fato que tornou a AIDS um acontecimento jornalístico digno de capa. Na edição 882 (31 jul. 1985), a revelação do caso do ator norte-americano Rock Hudson rendeu manchete secundária: Aids: o drama de Rock Hudson. Inicialmente associada a um câncer, a doença do Hudson, galã e primeira pessoa famosa no mundo a admitir publicamente a doença, chamou a atenção "[...] para a devastação da AIDS e o caráter epidêmico com que ela avança." (A SOMBRA..., 1985, p. 88).

A partir daí, a Veja oscilou a produção de capa, geralmente, entre zero e três textos por ano, com picos de quatro em três momentos. 0 primeiro deles foi em 1985, fase de "descoberta" da doença, quando se enfatizou o medo e as incertezas de uma patologia pouco conhecida que ocasionava mortes em todos os infectados. Em 1996 e 2009, houve momentos de alta, porém os textos mencionavam de forma transversal, dentro de outro assunto. A morte aparecia como mote dos enunciados de capa e das reportagens até o fim dos anos 1980. Nos anos 1990, "morrer" deu lugar ao verbo "pegar", em função da infecção pelo vírus do HIV. Exemplo disso pode ser visto nas duas capas da Figura 3. 
Figura 3 - Capas sobre HIV/AIDS enfatizando a infecção de Veja, 1991 e 1998

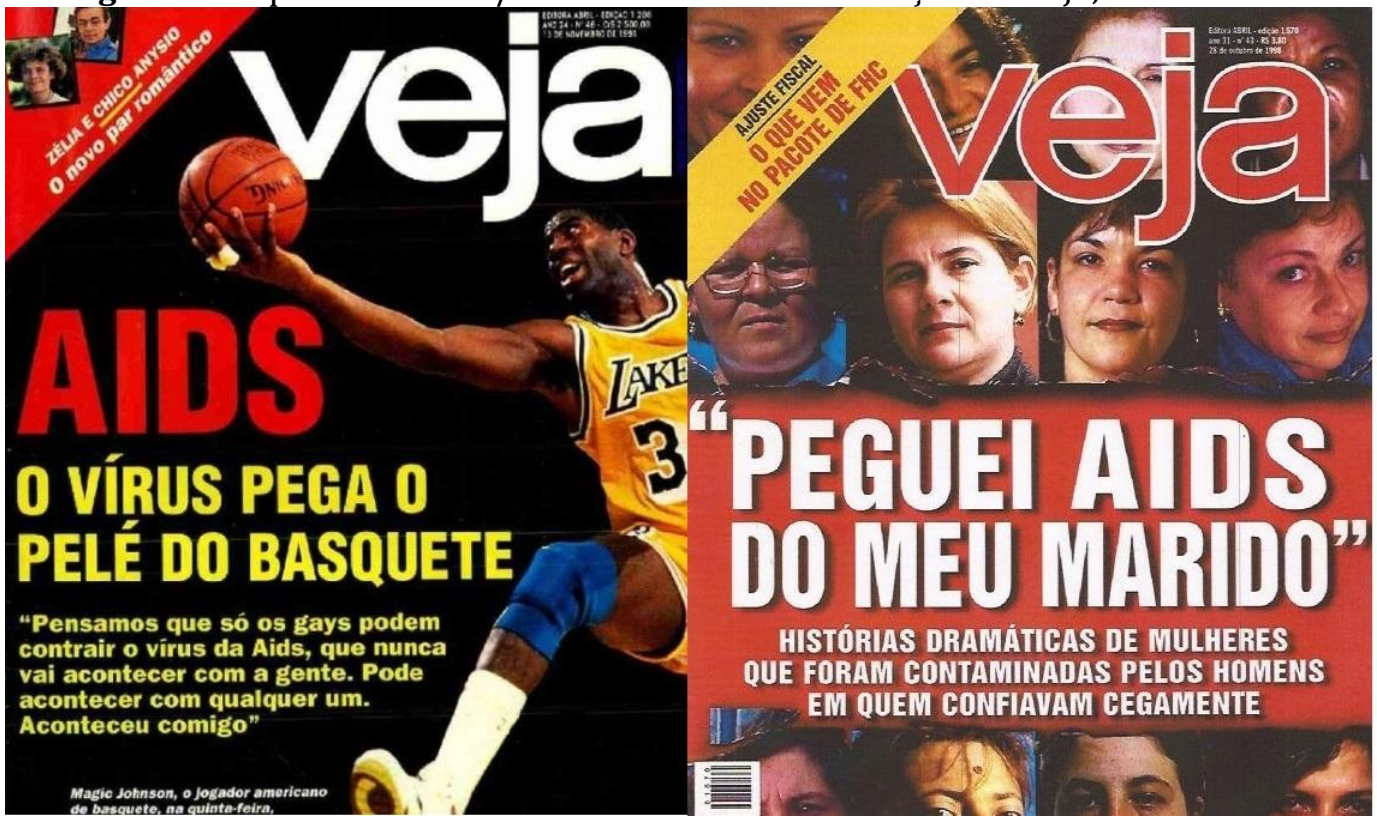

Fonte: Adaptado de Veja (1991; 1998), ed. 1208, 13 nov. 1991, e ed. 1570, 28 out. 1998.

0 verbo "pegar" significa "transmitir-se por contato", "atingir" e, principalmente, "adquirir doença por contágio", conforme alguns significados do termo no Houaiss (2009, p. 1.458). Sabendo que a convivência com o vírus é para toda a vida (ao menos enquanto uma cura não é descoberta), ele se "adere" simbolicamente ao doente para dar significado à noção de doença. Então, além do vírus, o doente e/ou o tumor (caso do câncer) passam a ser significantes também da doença; uma espécie de metonímia projetada entre a doença e o doente. Como figura de retórica, a metonímia consiste no uso de uma palavra fora do seu contexto semântico normal por outra, estabelecendo uma relação de contiguidade entre o termo substituído e o substituinte (FIORIN, 2008).

No jornalismo, as imagens são fundamentais para garantir sentido e maior impacto ao assunto abordado. A princípio, poderíamos pensar que as fotos são usadas para ilustrar as reportagens. Como estamos no universo das representações no qual o jornalismo se insere, esse recurso também é uma maneira de conferir sentido à doença através da imagem do personagem ou do organismo causador. Na intenção de revelar a realidade da doença através da imagem da pessoa infectada ou acometida por um tumor, a revista contribui por personificar o patológico no doente. Por isso, o verbo "pegar" é sintomático para a "união" que se faz entre os dois corpos: o do agente causador da patologia (ou agentes, pensando na multicausalidade das doenças crônicas) e do sujeito que foi "pego" por ela. 
No HIV/AIDS, a ideia da infecção que começou a circular no Brasil nos anos 1990 foi ampliada para fora dos grupos de risco. Na capa da edição 1208, na imagem à esquerda da Figura 3, sobre a revelação que o jogador de basquete norte-americano Magic Johnson estava com o vírus ("AIDS: o vírus pega o Pelé do basquete"), a declaração dele entre aspas escrita em amarelo é representativa: "Pensamos que só os gays podem contrair o vírus da AIDS, que nunca vai acontecer com a gente. Pode acontecer com qualquer um. Aconteceu comigo." (AIDS, 1991). Mais uma vez, o preto é a cor de fundo da primeira página, denotando não apenas a morte, mas também um sinal de alerta, considerando que a sua junção com o amarelo costuma reforçar um sentido de atenção - geralmente negativo sobre o que está sendo dito, conforme diz Heller (2013), neste caso o começo de uma nova fase do jogador com o HIV.

A principal diferença está na ousadia do atleta em expor a sua situação, uma conotação positiva ao relato, diferentemente de Hudson, que admitiu a doença só no leito de morte. O contexto de 1985 e o de 1991 são importantes para analisarmos a atitude das celebridades, em função das informações disponíveis e a forma de a sociedade encartar o contágio. Outra diferença está na contaminação do jogador, segundo a Veja, fora dos grupos de risco. Na época de Hudson, a AIDS era uma doença "[...] implacavelmente terminal e que ataca principalmente os homossexuais." (A SOMBRA..., 1985, p. 88). A revelação de Johnson foi mote para falar sobre o aumento da doença entre heterossexuais.

Na abordagem "fora" dos grupos de risco, a capa da edição 1570, imagem à direita da Figura 3, traz uma fotomontagem com 12 mulheres. A manchete Peguei AIDS do meu marido resume as declarações de todas, complementada pelo sutiã (frase abaixo do título): Histórias dramáticas de mulheres que foram contaminadas pelos homens em quem confiavam cegamente (VEJA, 1998). Escritos em branco, ambos são destacados pelo fundo vermelho, que pode ser "lido" simbolicamente como sangue.

Apesar de boa parte das entrevistadas ser portadora do vírus, a revista enquadra todas como doentes. 0 verbo "pegar" simboliza a metáfora da infecção, uma forma de qualificar o estilo do texto e, no discurso, de persuadir o público, impondo opiniões através do emprego de uma palavra com sentido diferente por analogia ou semelhança (CHARAUDEAU; MAINGUENEAU, 2008). Sontag (1989) diz que, em geral, as metáforas “[...] rotineiramente apresentam a doença como algo que invade a sociedade, e as tentativas de reduzir a mortalidade causada por uma doença são chamadas de lutas e guerras." (SONTAG, 1989, p. 14). 
No noticiário da Veja, a depressão veio por último. Aparecendo nas reportagens de capa em 1980, só foi assunto principal de primeira página na edição 1591 (31 mar. 1999). Antes, veio associada a outras doenças, inclusive à AIDS e ao câncer. A capa Depressão: a luta contra a doença da alma (ed. 1591) informa que o medicamento é a forma de "vencer" a "inimiga" que ataca a alma. Outras reportagens ressaltaram o benefício da medicação para controlar a doença ou prometer a cura. 0 período de 2002 a 2013 foi mais significativo. Com textos anuais entre quatro (mínimo) e nove (máximo), surgiu como tema principal ou diretamente ligado ao tema principal, numa média de dois textos/ano.

Na Figura 4, a diagramação das duas primeiras páginas da reportagem da edição 1757 (VEJA, 2002) enfoca o desenvolvimento de remédios, ao mostrar a mão de um pesquisador segurando uma molécula em que se vê rostos replicados de cientistas.

Figura 4 - Ênfase aos medicamentos na abordagem à depressão de Veja, 2002

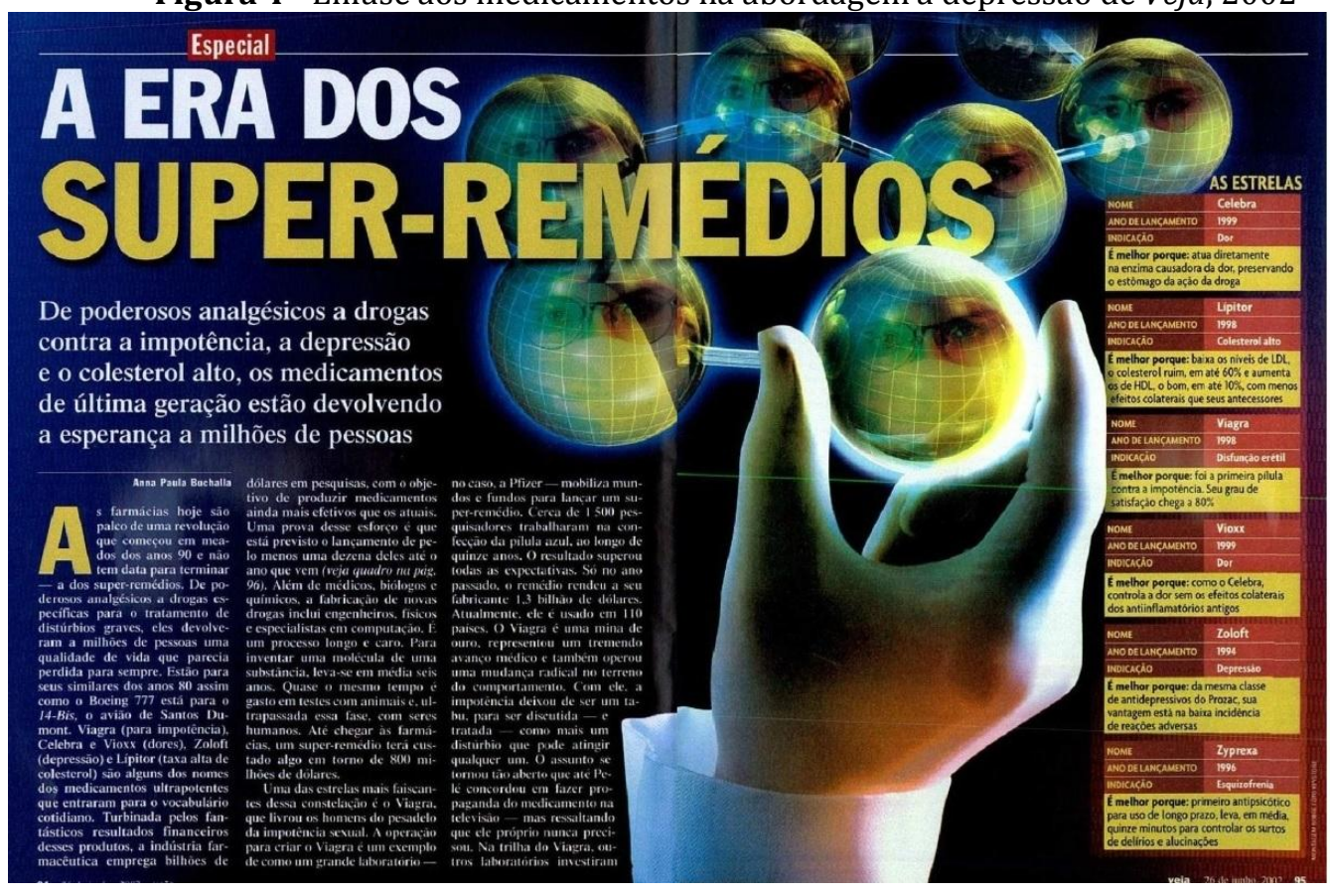

Fonte: Adaptado de Veja (2002), ed. 1757, 26 jun. 2002.

Apoiando-se em dados da indústria farmacêutica, a revista reforça a potência das novas drogas na intenção de enfatizar a efetividade dos seus efeitos. 0 intuito é construir um cenário para a enunciação que chame a atenção para a importância da pesquisa e confira credibilidade à indústria. A manchete salienta isso ( $A$ era dos super-remédios). Enfocando nos medicamentos de última geração a serem lançados, o sutiã (a frase situada abaixo da 
manchete) e a reportagem, na Figura 4, ressaltam o poder dos novos remédios no tratamento de doenças como a depressão, devolvendo esperança a milhões de pessoas.

Num cenário em que o sujeito está cada vez mais à mercê de definições institucionais e formas de tratamento oferecidas pelo domínio médico, os antidepressivos assumem um lugar especial no tratamento. Uma terapêutica atravessada por uma lógica medicalizante que busca reestabelecer a normalidade mental através de objetos técnicos, externos ao sujeito, como os fármacos, demandando um autocontrole do indivíduo.

Enquadrados pela psiquiatria como consumidores de remédios e/ou de estilos de vida, as pessoas passam a se inserir num mundo em que "[...] ficar triste, comer demais, fazer uso de cigarros ou drogas, ter dificuldades de concentração são consideradas mazelas físicas, localizadas no corpo e originadas nos genes." (FERREIRA, 2011, p. 89). Assim, o medicamento representa a solução para reverter o quadro, um produto capaz de resolver praticamente todos os problemas psíquicos, aliviando a dor e o sofrimento humanos.

0 enfoque no desenvolvimento de novas drogas faz parte do contexto de uma maior presença da ciência nas reportagens da Veja, sobretudo entre os anos de 1996 e 2014. Chamando a atenção para novidades em estudo ou em via de lançamento, esse atravessamento da ciência nas pautas seria, conforme Tucherman e Ribeiro (2006), uma estratégia discursiva para conferir maior prestígio e atualidade à mídia e garantir visibilidade à ciência, justificando socialmente a sua importância.

As capas da Veja que tratam de saúde nos anos 2000 enfatizam o novo e a descoberta (FRANÇA, 2011). Nelas, a ciência surge como a solução dos problemas de maneira objetiva, além de ter forte olhar econômico. Colocando-se como detentor de um saber específico, o jornalismo constrói o seu discurso apresentando soluções práticas para assegurar a qualidade de vida. Nessa lógica econômica, a revista produz sua ideia de saúde a partir do acesso à tecnologia para tratar ou evitar doenças, já que a técnica surge como alternativa para prolongar a vida, prevenindo da morte.

A avaliação do conjunto das reportagens acerca do câncer, do HIV/AIDS e da depressão é indicativa de parte importante das transformações ocorridas com a abordagem à doença. Mesmo sendo de diferentes grupos de patologias, é interessante notar como o aspecto social foi cedendo lugar, pouco a pouco, ao individual nos determinantes da doença dentro das pautas jornalísticas. Então, se nos anos 1970 a falta de recursos do Estado era apontada pela Veja como um dos fatores para "uma tragédia brasileira" do câncer (VEJA, 
1973), nos anos 1990 a "era dos super-remédios" (VEJA, 2002) é marcada pelos hábitos de vida do sujeito via consumo de remédios, denotando a responsabilização individual.

\section{Considerações finais}

O jornalismo se coloca ao lado de outras instâncias, como a medicina e a ciência, contribuindo à sua maneira para construir a ideia do que vem a ser doença hoje em dia: uma experiência cada vez mais crônica e medicalizada por meio de remédios e/ou determinados estilos de vida, metaforizados à condição de medicamentos. Mesmo não sendo um saber primeiro, produtor do conhecimento científico sobre o patológico, o jornalismo constrói o seu conhecimento na interseção de conhecimentos de várias esferas, indo desde o leigo até o científico. Nesse entremeio, ele se coloca como uma praça pública (FAUSTO NETO, 1999), para onde ele faz convergir as diferentes vozes convocadas a falarem sobre o assunto.

A análise das diferentes temporalidades na cobertura da Veja sobre o câncer, o HIV/AIDS e a depressão indicou as mudanças ocorridas com os discursos da revista. Do aspecto social, ressaltando as questões estruturantes relacionadas aos determinantes da doença, o noticiário foi cedendo espaço para o aspecto individual, responsabilizando o sujeito pela sua saúde e convidando-o a adotar novos hábitos. É uma visada discursiva que, para além da tradicional finalidade da informação do contrato de comunicação de "fazer saber" (CHARAUDEAU, 2006), parece se aproximar também do objetivo da incitação, comum ao discurso propagandístico, na intenção de "mandar fazer" e "mandar pensar".

Numa sociedade que valoriza a felicidade, a ênfase aos remédios é uma forma de valorizar o retorno da qualidade de vida perdida com a doença. Tendo a doença significados particulares de acordo com a cultura e a história de cada povo e época, analisá-la na perspectiva do jornalismo é se debruçar sobre parte importante do processo de construção sociocultural acerca do patológico. 0 presente trabalho representa um pequeno fragmento da problematização da categoria doença na sua relação com o jornalismo para a compreensão de parte dos sentidos produzidos na atualidade. Que os resultados e as reflexões possam instigar outras problematizações e sejam úteis na realização de novos estudos, levando-se em conta os diferentes contextos que envolvem a questão. 


\section{Agradecimentos}

Contamos com o apoio e a orientação do estatístico francês Olivier Georger na coleta, no tratamento e na checagem dos dados, bem como na concepção dos gráficos.

\section{Financiamento}

A pesquisa foi financiada pelas bolsas do Programa Nota 10 da Fundação Carlos Chagas Filho de Amparo à Pesquisa do Rio de Janeiro (Faperj) e do Programa de Doutorado Sanduíche no Exterior da Coordenação de Aperfeiçoamento de Pessoal de Nível Superior (Capes), Processo n. 99999.014278/2013-08.

\section{Referências}

A SOMBRA da AIDS. Veja, São Paulo, n. 882, p. 88-93, 31 jul. 1985.

AIDS: o vírus pega o Pelé do basquete. Veja. São Paulo: Abril, ed. 1208, n. 46, 13 nov. 1991. Semanal.

ANTUNES, E. 0 jornalismo é história malfeita? In: LEAL, Bruno Souza; ANTUNES, Elton; VAZ, Paulo Bernardo. Para entender o jornalismo. Belo Horizonte: Autêntica, 2014. p. 155-68.

ARONOWITZ, R. A. The converged experience of risk and disease. The Milbank Quarterly, Malden, v. 87, n. 2, p. 417-42, 2009.

BENETTI, M. A ironia como estratégia discursiva da revista Veja. Líbero, São Paulo, v. 10, n. 20, p. 37-46, dez. 2007.

BENETTI, M. Revista e jornalismo: conceitos e particularidades. In: TAVARES, Frederico de Mello; SCHWAAB, Reges (Org.). A revista e seu jornalismo. Porto Alegre: Penso, 2013. p. 44-57.

BERTUCCI, L. M. Influenza, a medicina enferma: ciência e práticas de cura na época da gripe espanhola em São Paulo. Campinas: Editora Unicamp, 2004.

BORCH-JACOBSEN, M. La fabrique des folies: de la psychanalyse au psychopharmarketing. Auxerre Cedex: Éditions Sciences Humaines, 2013. 
BRASIL. Ministério da Saúde. Instituto Nacional do Câncer. Estimativa 2014: incidência de câncer no Brasil. Rio de Janeiro: Instituto Nacional do Câncer José Alencar Gomes da Silva, 2014.

CAMARGO JÚNIOR, K. R. Medicalização, farmacologização e imperialismo sanitário. Cadernos de Saúde Pública, Rio de Janeiro, v. 29, n. 5, p. 844-6, maio 2013.

CASTIEL, L. D.; GUILAM, M. C. R.; FERREIRA, M.. Correndo o risco: uma introdução aos riscos em saúde. Rio de Janeiro: Fiocruz, 2010.

CHARAUDEAU, P. Discurso das mídias. São Paulo: Contexto, 2006.

CHARAUDEAU, P. Linguagem e discurso: modos de organização. São Paulo: Contexto, 2009.

CHARAUDEAU, P; MAINGUENEAU, D. Dicionário de análise do discurso. 2. ed. São Paulo: Contexto, 2008.

CLARK, L. G. de O.. 0 câncer nas capas da Veja: embasamento científico das reportagens (1973-2011). 2013. Dissertação (Mestrado em Divulgação Científica e Cultura) - Instituto de Estudos da Linguagem, Universidade Estadual de Campinas, Campinas, 2013.

CLARKE, A. et al. Biomedicalization: Technoscientific transformations of health, illness and u.s. biomedicine. American Sociological Review, [s.l.], v. 68, n. 2, p. 161-94. Apr. 2003.

CONRAD, P. Medicalization and social control. Annual Review of Sociology, Waltham, v. 18, n. 1, p. 209-232, Aug. 1992.

CONRAD, P. The medicalization of society: on the transformation of human conditions into treatable disorders. Baltimore. Maryland: The Johns Hopkins University Press, 2007.

CONRAD, P.; SCHNEIDER, J. Deviance and medicalization: from badness to sickness. Philadelphia: Temple University Press, 1980.

COUTINHO, D.; ALMEIDA FILHO, N. de; CASTIEL, L. D. Epistemologia da epidemiologia. In: BARRETO, M. L.; ALMEIDA FILHO, N. de. Epidemiologia e saúde: fundamentos, métodos e aplicações. São Paulo: Guanabara Koogan, 2011. p. 29-42.

EHRENBERG, A. Depressão, doença da autonomia? Ágora: estudos em teoria psicanalítica. Entrevistador: Michel Botbol. Rio de Janeiro, v. 7, n. 1, p. 143-53, jan./jun. 2004.

FARIAS, E. A. de. Jornalismo à espanhola: um olhar sobre o noticiário recifense da epidemia de gripe de 1918. 2008. Dissertação (Mestrado em Comunicação) - Universidade Federal de Pernambuco, Recife, 2008.

FAUSTO NETO, A. Comunicação e mídia imprensa: estudo sobre a AIDS. São Paulo: Hacker Editores, 1999.

FERRAZ, L. M. R. Doença, uma noção (também) jornalística: estudo cartográfico do noticiário de capa do semanário de informação Veja (1968-2014). 2015. Tese (Doutorado 
em Informação e Comunicação em Saúde) - Programa de Pós-graduação em Informação e Comunicação em Saúde, Instituto de Comunicação e Informação Científica e Tecnológica em Saúde, Fundação Oswaldo Cruz, Rio de Janeiro, 2015.

FERREIRA, S. A evolução do conceito de depressão no século XX: uma análise da classificação da depressão nas diferentes edições do Manual Diagnóstico e Estatístico da Associação Americana de Psiquiatria (DSMs) e possíveis repercussões destas mudanças na visão de mundo moderna. Revista Hospital Universitário Pedro Ernesto, Rio de Janeiro, v. 10, n. 2, p. 78-91, abr./jun. 2011.

FIORIN, J. L. Elementos da análise do discurso. 14. ed. São Paulo: Contexto, 2008.

FOUCAULT, M. A arqueologia do saber. 7. ed. Rio de Janeiro: Forense, 2007.

FOUCAULT, M. 0 nascimento da clínica. 6. ed. Rio de Janeiro: Forense, 2006.

FRANÇA, R. 0. 40 anos em revista: representações e memória social nas capas de Veja. 2011. Tese (Doutorado em Comunicação Social) - Faculdade de Filosofia e Ciências Humanas, Universidade Federal de Minas Gerais, Belo Horizonte, 2011.

GALTUNG, J.; RUGE, M. H.. The structure of foreign news. Journal of Peace Research, [s.l.], v. 1 , n. 1, p. 64-90, 1965.

HELLER, E. A psicologia das cores: como as cores afetam a emoção e a razão. São Paulo: Gustavo Gili, 2013.

HOHENBERG, J. Manual de jornalismo. Rio de Janeiro: Fundo de Cultura, 1962.

JURBERG, C. et al. Perfis das notícias sobre câncer no Correio da Manhã e no The New York Times nos anos 1931-1932 e 1948-1949. Revista Brasileira de Cancerologia, Rio de Janeiro, v. 58, n. 2, p. 143-52, abr./maio/jun. 2012.

Koifman, S.; Koifman, R. J. Environment and cancer in Brazil: an overview from a public health perspective. Mutation Research, Amsterdam, v. 544, n. 2-3, p. 305-11, nov. 2003.

LAGE, L. 0 acontecimento é o passado da notícia? In: LEAL, B. S.; ANTUNES, E.; VAZ, P. B. F. Para entender o jornalismo. Belo Horizonte: Autêntica, 2014. p. 77-88.

MOULIN, A. M. O corpo diante da medicina. In: CORBIN, A.; COURTINE, J-J.; VIGARELLO, G. (Org.). História do corpo: as mutações do olhar: o século XX. 3. ed. Petrópolis: Vozes, 2009. v. 3, p. 15-82.

NEIVA, P. Malignos, comuns e traiçoeiros. Veja, São Paulo, ed. 1830, n. 47, p. 144-151, 26 nov. 2003.

PEGAR. In: HOUAISS, A. Dicionário Houaiss da língua portuguesa. Rio de Janeiro: Objetiva, 2009. p. 1.458.

PEGUEI AIDS do meu marido. Veja, São Paulo, ed. 1570, n. 44, 28 out. 1998. Semanal. 
PORTELA, C. Revistas semanais de informação geral no Brasil hoje: conceituações e definições. In: COLÓQUIO INTERNACIONAL DE COMUNICAÇÃO PARA O DESENVOLVIMENTO REGIONAL, 14., 2009, São Paulo. Anais... São Paulo: Universidade Metodista de São Paulo, 2009. p. 1-15.

ABRIL. Veja. São Paulo: PubliAbril: circulação geral, 2017.

RIBEIRO, A. P. G.. A mídia e o lugar da história. In: HERSCHMANN, M.; PEREIRA, C. A. (Org.). Mídia, memória e celebridades. 2. ed. Rio de Janeiro: E-papers, 2005. p. 105-129.

SAINT CLAIR, E. T. A depressão como atualidade midiática no Brasil contemporâneo: fazendo o arquivo falar (1970-2010). 2012. Tese (Doutorado em Comunicação) - Escola de Comunicação, Universidade Federal do Rio de Janeiro, Rio de Janeiro, 2012.

SCALZO, M. Jornalismo de revista. 4. ed. São Paulo: Contexto, 2011.

SODRÉ, M. A narração do fato: notas para uma teoria do acontecimento. Petrópolis: Vozes, 2009.

SONTAG, S. AIDS e suas metáforas. São Paulo: Companhia das Letras, 1989.

SOUZA, C. M. C. de. A gripe espanhola na Bahia: saúde, política e medicina em tempos de epidemia. 2007. Tese (Doutorado em História das Ciências da Saúde) - Programa de PósGraduação em História das Ciências e da Saúde, Casa de Oswaldo Cruz, Rio de Janeiro, 2007.

SPINK, M. J. et al. A construção da AIDS-notícia. Caderno de Saúde Pública, Rio de Janeiro, v. 17, n. 4, p. 851-62, jul./ago. 2001.

TABAKMAN, R. A saúde na mídia: medicina para jornalistas, jornalismo para médicos. São Paulo: Summus Editorial, 2013.

TUCHERMAN, I.; RIBEIRO, M. S. Ciência e mídia: negociações e tensões. Revista ECO-Pós, Rio de Janeiro, v. 9, n. 2, p. 244-59, jan./jul. 2006.

VAZ, P. Doença mental e consumo nas revistas semanais brasileiras. E-compós, Brasília, v. 15, n. 1, p. 1-16, jan./abr. 2012.

VAZ, P.; PORTUGAL, D. A nova "boa-nova": marketing de medicamentos e jornalismo científico nas páginas da revista brasileira Veja. Comunicação, Mídia e Consumo, São Paulo, v. 9, n. 26, p. 37-60, nov. 2012.

VAZ, P.; PORTUGAL, D. A felicidade segundo a razão farmacêutica: subjetividade, tecnologia e consumo de medicamentos na cultura contemporânea. In: RIBEIRO, Ana Paula Goulart; FREIRE FILHO, J.; HERSCHMANN, M. (Org.). Entretenimento, felicidade e memória: forças moventes do contemporâneo. Guararema: Anadarco, 2013. p. 87-113.

VEJA. São Paulo: Abril, ed. 239, n. 14, 4 abr. 1973. Semanal. 
VEJA. São Paulo: Abril, ed. 1440, n. 16, 17 abr. 1996. Semanal.

VEJA. São Paulo: Abril, ed. 1757, n. 25, 26 jun. 2002. Semanal.

VEJA. São Paulo: Abril, ed. 1830, n. 47, 23 nov. 2003. Semanal.

WILLIAMS, S.; MARTIN, P.; GABE, J. The pharmaceuticalisation of society? A framework for analysis. Sociology of Health and Illness, Leeds, v. 33, n. 5, p. 710-25, jul. 2011.

ZOLA, I. K. Medicine as an institution of social control. The Sociological Review, Keele, v. 20, n. 4, p. 487-504, nov. 1972.

\title{
The disease in journalism: analysis of the news cover of Brazilian magazine Veja (1968- 2014)
}

\begin{abstract}
Journalism is nowadays an area of crucial importance to understand the notions of health and disease. With this view, we use the Brazilian weekly magazine Veja as empirical object, where we investigated the covers issued from 1968 to 2014, aiming the idea of disease framed by the magazine. In the first instance, we quantitatively examine the coverage related to health issues and general news. Then, we qualitatively deepen the analysis, focusing on the three most reported diseases of the major groups of pathologies: cancer (chronic degenerative), HIV/AIDS (infectious contagious) and depression (mental disorders). Though they belong to distinct groups, chronicity is the main characteristic that brings them closer. Emphasizing the medicalization and chronic care, Veja strengthens the reader's weight towards self-regulation as a form of control and / or prevention.
\end{abstract}

\section{Keywords}

Disease. Health. Journalism. Medicalization. Veja magazine.

Recebido em 16/03/2018

Aceito em 05/07/2018 